\title{
As editoras universitárias no contexto da educação superior pública brasileira
}

\author{
Sônia Maria Rezende Paolionelli ${ }^{I}$ \\ Beatriz Gaydeczka ${ }^{I I}$ \\ Luiz Fernando Resende dos Santos Anjo ${ }^{I I I}$
}

IUniversidade Federal do Triângulo Mineiro, Uberaba, MG, Brasil.

Bibliotecária/Documentalista na Universidade Federal

do Triângulo Mineiro (UFTM). Mestre em Inovação

Tecnológica pelo Programa de Mestrado Profissional

em Inovação Tecnológica da UFTM.

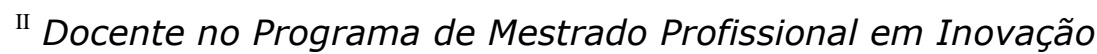

Tecnológica da Universidade Federal do Triângulo Mineiro,

Departamento de Engenharia Química. Doutora em Letras.

${ }^{I I I}$ Docente no Programa de Mestrado Profissional em Inovação

Tecnológica da Universidade Federal do Triângulo Mineiro, Departamento de Engenharia Civil. Programa de Mestrado

Profissional em Inovação Tecnológica - PMPIT. Doutor em Engenharia Civil.

http://dx.doi.org/10.1590/1981-5344/3134

Aborda as editoras universitárias públicas federais e estaduais brasileiras, como ambientes associados à produção e disseminação do conhecimento científico. Os avanços das novas Tecnologias de Informação e Comunicação estão influenciando a produção editorial, promovendo inovações em todas as etapas da cadeia produtiva do livro. O objetivo é apresentar uma análise da atuação das editoras universitárias no contexto da educação superior pública brasileira. A metodologia envolveu uma abordagem quantitativa e a população selecionada consiste de 47 dirigentes das editoras universitárias, dos quais se obteve o retorno de 16 questionários. Na coleta de dados utilizou-se um questionário eletrônico (Google Docs), com perguntas abertas e fechadas, enviado via e-mail no período de fevereiro a março de 2016. Os resultados mostram que algumas editoras universitárias estão organizadas para atender às demandas por publicação de recursos 
informacionais e outras, gradativamente, estão se inserindo no cenário editorial eletrônico por meio de inovações proporcionadas pelas novas Tecnologias de Informação e Comunicação. Os resultados permitem aos interessados no tema observar, fazer comparações e adaptações para implantar ou implementar novas editoras, baseadas na experiência das editoras pesquisadas.

Palavras-Chave: Editoras universitárias. Inovação tecnológica. Inovação editorial. Tecnologias de Informação e Comunicação. Ensino Superior.

\section{The university presses in the context of the Brazilian public higher education}

Addresses the Brazilian federal and state university presses as environments associated to the production and dissemination of scientific knowledge. The advance of new Information and Communication Technologies is influencing the editorial production, promoting innovations in all the stages of the production chain of the book. The aim is to bring an analysis of the performance of university presses in the context of the Brazilian public higher education. The methodology involved a quantitative approach and the selected population consists of 47 managers of university presses, from which it was obtained 16 answered questionnaires. In the data collection, was used an electronic questionnaire (Google Docs), with open and closed questions, sent by e-mail, from February 18 to March 18, 2016. The results show that some university presses are organized to attend the demands for publication of informational resources, and others, are gradually entering the electronic publishing scenario, by means of innovations provided by the new Information and Communication Technologies. These data allow those interested in the topic to observe, make comparisons and adaptations to implant or implement new publishers, based on the experience of the researched presses.

Key Words: University presses. Technological innovation. Editorial innovation. Information and Communication Technologies. Higher Education. 


\section{Introdução}

Os ambientes universitários estão associados à produção e disseminação do conhecimento científico, e neles, tanto as editoras universitárias (EUs) quanto as bibliotecas universitárias devem ser espaços de apoio utilizados pelas Instituições de Ensino Superior (IES), para cumprir sua missão de construção e socialização do saber.

Neste contexto, as editoras e bibliotecas universitárias têm atribuições que se correlacionam, uma vez que, às EUs, cabe o papel de receber as publicações dos autores, transformá-las em produtos editoriais de qualidade e adotar meios eficazes para divulgá-los; já às BUs cabem o tratamento e a disseminação das informações no contexto acadêmico.

Enquanto responsáveis por desenvolver, em interação e integração, o tripé ensino, pesquisa e extensão, as IES devem buscar caminhos para disponibilizar à sua comunidade acadêmica, canais para a divulgação das pesquisas científicas, em especial, a editora universitária. Este artigo investiga como as EUs estão inseridas no cenário editorial brasileiro, descrevendo esse campo editorial aos dirigentes das IES, para intervenções, melhorias e/ou adequações no seu ambiente institucional.

$\mathrm{O}$ crescimento e a evolução do mercado editorial, alicerçados pelas novas tecnologias de informação e comunicação (TICs), promovem mudanças importantes neste cenário, uma vez que a transição da cultura impressa para a cultura digital possibilita a ampliação da divulgação, distribuição, promoção e acesso ao conhecimento.

A influência das inovações tecnológicas na atividade editorial contribuiu para o desenvolvimento de um novo cenário, com o surgimento de novos produtos editoriais, novas formas de distribuição e comercialização, além de impactar os novos hábitos de leitura dos consumidores, com o uso de diferentes suportes de leitura, sejam eles físicos, eletrônicos ou digitais.

Neste contexto, ressalta-se a atuação do Instituto Brasileiro de Informação em Ciência e Tecnologia (IBICT) como pioneiro no desenvolvimento de inovações tecnológicas de acesso aberto no Brasil, principalmente, com os projetos Biblioteca Digital Brasileira de Teses e Dissertações (BDTD) e os Repositórios Institucionais (RIs), contribuindo para a organização e a disseminação do conhecimento no âmbito das universidades.

Outra importante iniciativa em relação ao acesso aberto, o Portal SciELO Livros, uma das primeiras iniciativas envolvendo as EUs brasileiras, vem se firmando como um forte programa de inclusão de $e$ books na Internet. O Portal SciELO Livros foi lançado em 2012, visando à publicação on-line de coleções de livros de caráter científico editadas, prioritariamente, por instituições acadêmicas (LUCCISANO et al., 2014).

A iniciativa SciELO Livros tem uma importância fundamental no cenário editorial brasileiro, pois fortalece e amplia a visibilidade de 
autores, de livros e das EUs, possibilitando a disseminação e o acesso ao conhecimento científico.

Este artigo objetiva apresentar uma análise da atuação das editoras universitárias no contexto da educação superior pública brasileira e, para isso, foram selecionadas 47 EUs para responder a um questionário eletrônico que abordou as seguintes dimensões: estrutura organizacional; equipe administrativa; política editorial; processo produtivo; linhas editoriais; comercialização e divulgação; tecnologia de informação e comunicação (TICs) utilizadas pelas EUs.

\section{Procedimentos metodológicos}

Esta pesquisa, de cunho exploratório, bibliográfica e descritiva, se caracteriza pelo reconhecimento da estrutura organizacional das EUs, por meio do registro de suas características organizacionais. Foi feito um levantamento de dados junto às EUs para se conhecer a forma como estão organizadas para atender às demandas por publicação de recursos informacionais impressos, eletrônicos e digitais ${ }^{1}$. Foram convidados a participar deste estudo 47 dirigentes de EUs públicas federais e estaduais brasileiras, selecionados mediante acesso à lista de EUs cadastradas no site da Associação Brasileira de Editoras Universitárias (ABEU), com ênfase nas editoras públicas federais e estaduais com data de criação até 1999. Acrescentou-se a esse grupo, duas editoras não associadas à ABEU devido à sua relevância institucional. Na coleta de dados utilizou-se um questionário eletrônico (Google Docs), elaborado pelos autores de forma semiestruturada. O questionário abordou oito dimensões, e para cada dimensão, foram elaboradas questões abertas, fechadas e do tipo aberta e fechada, que permitiram a análise de variáveis numéricas e categóricas. 0 instrumento de coleta de dados foi enviado via e-mail aos dirigentes das EUs, no período de fevereiro a março de 2016. Após a distribuição dos 47 questionários para os dirigentes das EUs, dos quais obteve-se um retorno de 16 dirigentes, ou seja, 34,04\% de adesão da população selecionada, índice estatisticamente significativo em relação aos dados da pesquisa. Para a análise e interpretação de dados, foi utilizada análise descritiva e análise de conteúdo das respostas dos participantes, relacionando-as com a literatura consultada. Os dados gerados pelo formulário eletrônico (Google Docs) foram exportados e analisados utilizando-se o programa Statistical Package for the Social Sciences (SPSS), versão 20.

\section{Resultados e Discussão}

Em relação à estrutura organizacional investigou-se a situação das EUs no organograma das IES e o vínculo hierárquico. A Tabela 1 demonstra que a maioria, ou seja, 62,5\% das EUs estão organizadas como órgão suplementar da Universidade e que $68,5 \%$ são subordinadas

Esta pesquisa foi aprovada pelo Comitê de Ética em Pesquisa da UFTM, com parecer favorável número 1.276.045, de 13 de out. 2015, tendo os participantes assinado o Termos de Consentimento Livre e Esclarecido (TCLE). 
diretamente à Reitoria, uma característica peculiar às unidades autônomas de apoio técnico-operacional.

Tabela 1 - Situação no organograma e vínculo hierárquico das EUs, Brasil, 2016

\begin{tabular}{lcr}
\hline Estrutura organizacional & $\mathbf{n}$ & $\mathbf{\%}$ \\
\hline Śituação na IES & & \\
Órgão Suplementar & 10 & 62,5 \\
Setor & 2 & 12,5 \\
Fundação & 2 & 12,5 \\
Diretoria & 1 & 6,3 \\
Departamento & 1 & 6,3 \\
& & \\
Vínculo hierárquico & & \\
Reitoria & 11 & 68,8 \\
Pró-Reitoria & 5 & 31,3 \\
Total & $\mathbf{1 6}$ & $\mathbf{1 0 0}$ \\
\hline \multicolumn{2}{l}{ Fonte: Elaborado pelos Autores } & 2016 \\
\end{tabular}

Bufrem (2001) salienta que o vínculo entre a editora e a instituição depende da filosofia da instituição e da definição de papéis atribuídos à EU e, sendo assim, infere-se que a IES julga a editora importante no contexto universitário e que é preciso estar bem próximo para apoiar o processo produtivo das EUs em todas as etapas.

Considerando que as IES públicas têm suas particularidades em relação à gestão de recursos e comercialização de seus produtos e serviços, procurou-se identificar a relação do Cadastro Nacional de Pessoas Jurídicas (CNPJ) entre IES e suas EUs. Segundo Brasil (2015), a obrigatoriedade de inscrição no CNPJ abrange "os órgãos públicos de qualquer dos Poderes da União, dos Estados, do Distrito Federal e dos Municípios, desde que se constituam em unidades gestoras de orçamento", justificando assim, que as IES sejam inscritas no CNPJ.

A Tabela 2 mostra que a maioria das EUs $(56,25 \%)$ utiliza o CNPJ da IES, enquanto $43,75 \%$ têm CNPJ independente. Infere-se que a gestão orçamentária das EUs que utilizam o CNPJ das IES, é feita pela própria IES e, não, de forma independente pela editora, o que pode dificultar o desenvolvimento de diferentes projetos, inclusive de parcerias com outras EUs.

A inscrição no CNPJ tem como vantagem agilizar e desburocratizar o processo de comercialização de mercadorias e a geração de renda própria para as EUs, tornando-as de alguma forma autossuficiente, produtiva e independente.

Sobre a atuação dos Conselhos editorial e deliberativo das EUs, constatou-se que todas possuem Conselho editorial e, apenas 18,75\% delas possuem Conselho Deliberativo, conforme detalhado na Tabela 2. Um Conselho ou Comissão editorial é responsável pela qualidade editorial e gráfica da produção científica da IES, ou seja, pela política editorial da EU e o Conselho deliberativo atua com a gestão, por meio da definição de 
políticas e estratégias gerais e o estabelecimento das diretrizes e normas de organização, operação e administração.

Em relação à atuação do diretor e ou presidente da EU constatou-se que em $87,5 \%$ das EUs, este profissional atua também como presidente do Conselho Editorial, acumulando as duas funções e corroborando o pensamento de Bufrem (2001) ao afirmar que isso é inadequado, tendo em vista que são funções distintas e com perfis específicos.

A Tabela 2 demonstra que o perfil dos dirigentes das EUs se caracteriza pela atividade acadêmica, $81,25 \%$ pertencem à categoria de professores das IES e, desses professores, por meio de consulta na Plataforma Lattes, em maio/2016, constatou-se $87,5 \%$ dos dirigentes são doutores, 62,5\% tem experiência com publicação de livros, 56,25\% já organizaram livros, $25 \%$ publicaram livros em coautoria com outros autores e, ainda, 81,25\% publicaram capítulos de livros.

Depreende-se que a experiência com publicações possibilita a aquisição de uma visão ampla da criação (literária, didática e técnicocientífica) e do processo produtivo, adquiridas por meio de vivências e dificuldades enfrentadas, capacitando para o exercício da função de dirigente de uma editora. Por outro lado, para os dirigentes com pouca ou nenhuma experiência com publicações, presume-se que a atuação destes tenha o foco na gestão, na produtividade e na sustentabilidade financeira da EU.

Tabela 2 - Utilização do Cadastro Nacional de Pessoas Jurídicas (CNPJ) pelas IES e suas EUs, e a atuação dos Conselhos Editorial e Deliberativo, Brasil, 2016

\begin{tabular}{|c|c|c|}
\hline Estrutura organizacional & $\mathbf{n}$ & $\%$ \\
\hline \multicolumn{3}{|c|}{ O CNPJ da editora é o mesmo da universidade? } \\
\hline Sim & 9 & 56,25 \\
\hline Não & 7 & 43,75 \\
\hline \multicolumn{3}{|l|}{ Possui Conselho Editorial? } \\
\hline Sim & 16 & 100 \\
\hline \multicolumn{3}{|c|}{ Possui Conselho Deliberativo? } \\
\hline Não & 13 & 81,25 \\
\hline Sim & 3 & 18,75 \\
\hline \multicolumn{3}{|c|}{$\begin{array}{l}\text { O Diretor/Presidente da editora é o } \\
\text { presidente do Conselho Editorial? }\end{array}$} \\
\hline Sim & 14 & 87,5 \\
\hline Não & 2 & 12,5 \\
\hline \multicolumn{3}{|c|}{ De quem é a decisão editorial? } \\
\hline Conselho/Comissão editorial & 14 & 87,5 \\
\hline Diretor/Presidente da EU & 1 & 6,25 \\
\hline Conselho deliberativo & 1 & 6,25 \\
\hline \multicolumn{3}{|c|}{ Qual era a atuação anterior do atual Editor? } \\
\hline Professor & 13 & 81,25 \\
\hline Técnico Administrativo & 3 & 18,75 \\
\hline Total & 16 & 100 \\
\hline
\end{tabular}


Fonte: Elaborado pelos Autores, 2016

Quanto ao tema papel da ABEU no cenário editorial brasileiro, os dados demonstram que ela incentivou a criação e o desenvolvimento de novas EUs, promoveu o intercâmbio por meio de encontros, debates e cursos, além de divulgar as publicações das associadas em feiras, no Brasil e no Exterior.

Neste sentido, das EUs que responderam ao questionário, apenas uma não é afiliada na $A B E U$ e $37,5 \%$ dos dirigentes responderam que são afiliados desde a fundação da ABEU e, sendo assim, possivelmente, participaram de sua criação. Ao serem questionadas sobre as vantagens de serem associadas à $A B E U$, as respostas sinalizam que as EUs a consideram um importante canal de interação na cadeia produtiva do livro universitário, proporciona a ampliação de sua representatividade, credibilidade e estabilidade no mercado editorial brasileiro, possibilitando a superação conjunta dos obstáculos apresentados pelo setor. Os dirigentes consideram importante o contato entre si; a comunicação e a divulgação de suas publicações; a promoção e o marketing como forma de dar visibilidade ao segmento e ampliar a sua abrangência.

A sustentabilidade das EUs é uma preocupação de muitas IES, tendo em vista as dificuldades financeiras pelas quais o ensino superior brasileiro sempre passou, principalmente por depender da esfera pública.

Ao identificar os recursos financeiros utilizados para as publicações, constatou-se que os Recursos próprios das EUs e os Recursos da Fundações de Apoio à Pesquisa são as opções utilizadas pela maioria, ambos apontados por $68,75 \%$ delas. Outros recursos apontados foram: recursos dos Programas de Pós-Graduação (62,5\%), apoio externo $(50 \%)$, recursos dos próprios autores $(43,75 \%)$. Isso confirma a dependência das EUs de recursos públicos e ressalta a necessidade de planejamentos que estimulem parcerias público-privadas e coedições, pois é possível uma EU ser autônoma e ter um programa editorial financiado com recursos próprios.

Em relação à equipe administrativa, foram investigados os cargos existentes na EU, a forma de seleção dos funcionários e a quantidade de funcionários da EU.

Ao longo dos anos, o trabalho nas editoras se tornou especializado, as equipes, formadas por profissionais multidisciplinares e qualificados dentro de suas especialidades, levou a produção de produtos editoriais diferenciados.

Constatou-se que os oito cargos de maior frequência são: Diretor/Presidente, 93,75\%; Revisor (87,5\%); Secretária executiva (75\%); Responsável pelas vendas (75\%); Designer gráfico $(68,75 \%)$; Responsável pelo estoque $(62,5 \%)$; Setor de produção $(62,5 \%)$; Serviços gerais $(56,25 \%)$.

Infere-se que, pelo fato de o cargo de editor ter frequência de apenas $31,25 \%$ no quadro de funcionários das EUs, o diretor/presidente acumula a função de editor. 
A baixa frequência ( $25 \%$ ) do profissional Bibliotecário constatada na pesquisa demonstra que algumas instituições não percebem a importância deste profissional ou desconhecem sua capacidade e potencialidades para o desenvolvimento dos serviços bibliotecários altamente requisitados pelas EUs. Ou ainda, que o Bibliotecário desconhece ou não tem interesse por esta área específica de atuação.

De acordo com estudos de Sampaio (1991) e Bufrem (2001), a classe bibliotecária esteve presente nos primeiros encontros das EUs, quando o setor ainda estava se organizando, discutindo e colaborando com a solução dos problemas das publicações oficiais, tais como direitos autorais, depósito legal, padronização, normalização e registro dos produtos editoriais em órgãos específicos de controle bibliográfico.

O tema produção editorial no âmbito das IES ocupa lugar de destaque no cenário editorial universitário brasileiro. Por isso, é fundamental instituir a política editorial, instrumento que estabelecerá os objetivos e responderá aos seguintes questionamentos: o que editar, para quem, como editar, quando publicar; e, onde publicar (ROSINHA, 1989).

Sobre a política editorial, verificou-se a forma de participação de programas de pós-graduação (PPGs) na política editorial das EUs, pois eles são responsáveis pela crescente atividade intelectual, incremento da pesquisa, produção e disseminação do conhecimento científico.

Este estudo comprovou que apesar de os PPGs não influenciarem diretamente as decisões das EUs, eles têm programas específicos para financiamento e captação de propostas de publicação, o que de certa forma favorece a aproximação com as EUs e possibilita a publicação de obras de interesse dos PPGs.

Ainda sobre a política editorial, investigou-se os tipos de publicações produzidas pelas EUs (coedições, e-books comerciais, e-books de acesso livre, traduções e adaptações).

A Tabela 3 evidencia que as EUs concordam com as vantagens da coedição, 87,5\% delas adotam este sistema, possibilitando a realização conjunta de produções diversas, por meio de contratos específicos e formais entre autores e editores.

As EUs vêm incorporando os avanços tecnológicos aos seus produtos editoriais, como forma de atender à demanda de acesso rápido e dinâmico à informação e ao conhecimento. As TICs, os recursos de hiperlinks e conteúdos interativos modificam o papel das EUs no mercado editorial eletrônico. A oferta de e-books tende a aumentar, devido ao baixo custo da publicação, e à EU caberá um papel relevante: de filtro, de afirmação e garantia de qualidade (FRANCHETTI, 2012).

Constatou-se que $37,5 \%$ das EUs publicam e-books comerciais enquanto $56,25 \%$ publicam e-books de acesso aberto, tais como no Portal SciELO Livros. Para Franchetti (2012) o livro universitário no formato eletrônico exige maiores cuidados, tais como revisão técnica, produção criteriosa e isso gera um custo alto. Por outro lado, o livro universitário não vende como um romance. Assim, a relação entre custo/retorno, no 
caso do livro universitário eletrônico, será muito diferente em comparação com uma editora de livros de tiragem ampla.

Quanto às traduções, constatou-se que $62,5 \%$ das EUs adota a tradução na sua política editorial. Na análise de Bufrem (2009) a prática de tradução de obras estrangeiras se justifica como forma de suprir as carências bibliográficas, uma vez que o Brasil carece de literatura de ponta em algumas áreas científicas pouco exploradas.

Tabela 3 - Política editorial das editoras universitárias, Brasil, 2016.

\begin{tabular}{lcc}
\hline Política editorial & $\mathbf{n}$ & $\mathbf{\%}$ \\
\hline Realiza coedições? & 14 & 87,5 \\
Sim & 2 & 12,5 \\
Não & & \\
Publica e-books comerciais? & 6 & 37,5 \\
Sim & 10 & 62,5 \\
Não & & \\
Publica e-books de acesso aberto? & 9 & 56,25 \\
Sim & 7 & 43,75 \\
Não & & \\
Publica traduções? & 10 & 62,5 \\
Sim & 6 & 37,5 \\
Não & & \\
Publica adaptações? & 2 & 12,5 \\
Sim & 14 & 87,5 \\
Não & $\mathbf{1 6}$ & $\mathbf{1 0 0}$ \\
Total & \multicolumn{2}{c}{2016} \\
\hline
\end{tabular}

Fonte: Elaborado pelos Autores, 2016

O processo produtivo das EUs enfrentam problemas relacionados à quantidade de títulos e exemplares a serem publicados. Porém, a quantidade de livros publicados por uma editora está diretamente relacionada a alguns fatores, tais como, o tamanho da IES, a localização geográfica, o poder aquisitivo da população atendida, os recursos tecnológicos disponíveis e o acesso aos canais de distribuição e divulgação.

Bufrem (2001, p. 207) acredita que "uma grande tiragem sem mecanismos de divulgação e circulação eficientes amplia fatalmente os estoques dos depósitos". Torna-se importante a seleção criteriosa dos títulos a serem publicados, a produção de livros mais atrativos com projetos gráficos sofisticados, conhecer o seu público e saber como chegar até ele (seja por livrarias físicas, eletrônicas ou redes sociais).

Para sanar o problema das tiragens da produção editorial, surgiu, há alguns anos, a opção print on demand $(P O D)$ que é a impressão do livro a partir de uma demanda. Para ilustrar esta solução Rodrigues et al. (2014), exemplifica a empresa Amazon.com. Ela divulga o título, recebe as solicitações e imprime os livros de acordo com a demanda dos usuários da plataforma. Esta solução tem possibilitado aos editores repensarem 0 número das tiragens dos livros publicados. 
Conforme constatado nesta pesquisa, apenas uma das editoras adota esta solução. Porém, Lindoso (2012) salienta que as editoras, em geral, desprezam meios que efetivamente reduzem custos. A preocupação com os custos de produção levaria a diminuir o preço dos livros ou a melhorar sua rentabilidade. Infere-se que as EUs não estão preocupadas em reduzir custos e estoques, melhorar as condições de logística e maximizar o alcance dos livros pelos usuários.

É importante que as EUs aproveitem as facilidades da impressão na era digital e adotem a produção de livros sob demanda em casos específicos, possibilitando a oportunidade de publicar tiragens menores e sem grandes riscos.

Em relação à Linha editorial, as EUs foram questionadas sobre os assuntos publicados, os tipos de publicações e a responsabilidade da editora quanto à publicação dos periódicos da Universidade.

A Tabela 4 demonstra que $43,75 \%$ das EUs publicam assuntos de todas as áreas do conhecimento. Em contrapartida, apenas $12,5 \%$ preocupam-se com temas regionais. Bufrem (2001) salienta a experiência editorial universitária, enquanto projeto cultural deve privilegiar as peculiaridades regionais, a conservação da cultura e os modos de vida das minorias.

Quanto aos tipos de publicações, a Tabela 4 revela que todas as editoras (100\%) publicam livros técnico-científicos e que $87,5 \%$ publicam livros didáticos para o ensino superior. Isso comprova o que Martins Filho; Rollemberg (2001), Bufrem (2001, 2009) afirmam sobre o fato de as EUs priorizarem obras cujos conteúdos atendam às necessidades imediatas dos currículos, enriquecendo as bibliografias de áreas específicas, com vistas a apoiar o ensino e a pesquisa.

A publicação de teses e dissertações, presentes em 43,75\% das EUs, reforça o princípio de que as EUs oportunizam a publicação da produção científica dos docentes da IES, valorizando-os e tornando-os conhecidos no mercado editorial universitário.

A publicação de periódicos científicos está presente em 43,75\% das EUs, demonstrando que estas publicações não são totalmente de responsabilidade das EUs. Periódicos científicos têm peculiaridades e, sua viabilidade, assim como os limites de responsabilidade, carece de maiores estudos, pois demandam um esforço maior da equipe em relação à pontualidade, periodicidade regular e rigor nos prazos de submissão, avaliação pelos pares, aprovação, normalização, diagramação e publicação. São publicações que, para serem reconhecidas pela comunidade científica nacional e internacional, passam por critérios rigorosos de qualidade científica e editorial, além dos registros em órgãos internacionais de controle bibliográfico. 
Tabela 4 - Linha editorial das editoras universitárias, Brasil, 2016.

\begin{tabular}{lcc}
\hline Variáveis & $\mathbf{n}^{\mathbf{( 1 )}}$ & $\mathbf{\%}$ \\
\hline Assuntos publicados & & \\
Ciências exatas e da terra & 8 & 50 \\
Ciências agrárias & 8 & 50 \\
Ciências humanas & 8 & 50 \\
Ciências biológicas & 8 & 50 \\
Ciências sociais e aplicadas & 8 & 50 \\
Ciências da Saúde & 8 & 50 \\
Engenharias & 7 & 43,75 \\
Linguística, Letras e Artes & 7 & 43,75 \\
Todos os assuntos & 7 & 43,75 \\
Temas regionais & 2 & 12,5 \\
Tipos de publicações & & \\
Livros técnicos científicos & 16 & 100 \\
Livros didáticos para o ensino superior & 14 & 87,5 \\
Manuais, guias, cartilhas & 9 & 56,25 \\
Teses e dissertações & 7 & 43,75 \\
Periódicos científicos & 7 & 43,75 \\
TCC & 3 & 18,75 \\
Relatórios de pesquisa & 2 & 12,5 \\
\hline
\end{tabular}

Fonte: Elaborado pelos Autores, 2016

Nota: (1) O n destas variáveis se refere à soma das respostas das EUs, sendo que foi possível mais de uma resposta por EU.

Sendo assim, a EU deve se organizar e se estruturar para tornar-se facilitadora nos processos de editoração, aprimorando a qualidade, padronização e zelando pela periodicidade regular de periódicos, trabalhando em sintonia com os programas de pós-graduação, fontes produtoras deste tipo de publicação.

Quanto aos canais de comercialização, distribuição e comunicação utilizados para o marketing institucional das EUs, a Tabela 5 traz dados sobre estas etapas da cadeia produtiva do livro. Tão importantes quanto as outras, as etapas devem ser bem planejadas para que os recursos informacionais se tornem conhecidos e cheguem às mãos do público leitor, seja por meio das livrarias, seja por qualquer outra estratégia de inovação editorial que agilize o processo de compra e venda de produtos no ambiente virtual.

A Tabela 5 demonstra que as EUs estão mesclando canais físicos e virtuais no processo de comercialização e distribuição de livros, tendo em vista o percentual de $43,75 \%$ de EUs que adotam o e-commerce.

Outros canais de comercialização, como livraria móvel e eventos locais e nacionais, foram citados por $12,5 \%$ das EUs. São opções importantes para a circulação dos livros e a visibilidade da editora, pois 
extrapolando os muros da EU possibilitam um contato maior com o público leitor.

Sobre os meios de comunicação utilizados para o marketing institucional das EUs, a Tabela 5 demonstra que Facebook e E-mail são os canais mais utilizados, uma vez apontados por $81,25 \%$ das EUs. Site institucional e Site institucional com catálogo on-line foram a segunda opção apontada por $75 \%$ das EUs. Twitter $(37,5 \%)$ e Blog $(18,75 \%)$ apesar de aparecerem com menor frequência devem ser ressaltados, tendo em vista suas importantes características para o atual contexto digital: instantaneidade, dinamicidade, interatividade.

Tabela 5 - Canais de comercialização e divulgação utilizados pelas editoras universitárias, Brasil, 2016.

\begin{tabular}{lcc}
\hline Comercialização e Divulgação & $\mathbf{n}^{(\mathbf{1})}$ & \% \\
\hline $\begin{array}{l}\text { Quais os canais de } \\
\text { comercialização e } \\
\text { distribuição de livros } \\
\text { adotados pela editora? }\end{array}$ & & \\
Livraria física (própria) & & \\
Livraria virtual (própria) & 14 & 87,5 \\
Outras livrarias (físicas) & 12 & 75 \\
Distribuidores & 12 & 75 \\
E-commerce & 9 & 56,25 \\
Outras $*$ & 7 & 43,75 \\
Não comercializa & 2 & 12,5 \\
Canais de comunicação & 1 & 6,25 \\
utilizados para o marketing & & \\
institucional da editora & & \\
Facebook & 13 & 81,25 \\
E-mail & 13 & 81,25 \\
Site institucional & 12 & 75 \\
Site institucional com catálogo & 12 & 75 \\
on-line & & \\
Twitter & 6 & 37,5 \\
Boletim informativo & 4 & 25 \\
Blog & 3 & 18,75 \\
TV & 3 & 18,75 \\
Emissora de rádio & 3 & 18,75 \\
Outdoor & 2 & 12,5 \\
Jornal de grande circulação & 1 & 6,25 \\
s/resposta & 1 & 6,25 \\
\hline
\end{tabular}

Fonte: Elaborado pelos Autores, 2016

Nota: $\left({ }^{1}\right)$ O n destas variáveis se refere à soma das respostas das EUs, sendo que foi possível mais de uma resposta por EU.

* Foram citadas outras formas de comercialização, tais como: Livraria móvel, Eventos locais e nacionais. 
Esses dados levam a refletir sobre a importância da adoção de novas práticas de mercado e, principalmente, sobre o uso eficaz das novas TICs como meios efetivos de comunicação, divulgação e comercialização das produções editoriais das EUs, em uma tentativa de superação das dificuldades de inserção e permanência em um novo ambiente de negócios implementado pelos formatos digitais contemporâneos.

Neste sentido, como forma de inovação editorial, cabe às EUs intensificar o uso das novas TICs para se inserir nesse ambiente digital, construir sites mais interativos, divulgar lançamentos de livros em várias mídias, adotar o e-commerce e conquistar novos clientes para além das fronteiras locais ou regionais.

\section{Conclusão}

Neste artigo procurou-se demonstrar que as EUs públicas federais e estaduais estão organizadas para atender às demandas de produção, publicação, divulgação e perpetuação do conhecimento científico, com algumas restrições, tais como: deficiências no quadro de funcionários, inexistência de bibliotecário, dependência de recursos financeiros governamentais, sustentabilidade e autonomia financeira não definida, falta de planejamento e investimentos em tecnologia para o exercício da função educacional das EUs e a indefinição da responsabilidade pela publicação de periódicos científicos das IES.

No que se refere à opção print on demand, disponibilização de conteúdos on line e produção de ebooks, é necessário fortalecer estas iniciativas, para que as EUs atendam às demandas mercadológicas por racionamento logístico (menores estoques), novos formatos e novas possibilidades de acesso rápido e dinâmico à informação e ao conhecimento.

Por fim, ressalta-se que a relevância científica e social desta pesquisa para a área da Ciência da Informação ficou evidenciada pelo reconhecimento das inovações editoriais proporcionadas pelas novas TICs no processo produtivo das EUs e, ainda, por disponibilizar informações, por meio das quais será possível observar, fazer comparações e adaptações para implementar novas editoras, baseadas na experiência das EUs já inseridas no mercado editorial universitário brasileiro.

\section{Referências}

BRASIL. Ministério da Fazenda. Secretaria da Receita Federal do Brasil. Quem está obrigado a se inscrever no CNPJ. Brasília, 2015. Disponível em:

http://idg.receita.fazenda.gov.br/orientacao/tributaria/cadastros/cadastro -nacional-de-pessoas-juridicas-cnpj/quem-esta-obrigado-a-se-inscreverno-cnpj. Acesso em: 20 jun. 2016. 
BUFREM, L. S. Editoras universitárias no Brasil: uma crítica para a reformulação da prática. São Paulo: EDUSP, 2001.

BUFREM, L. S. Política editorial universitária: por uma crítica à prática. Perspectivas em Ciência da Informação, Belo Horizonte, v. 14, n. 1, p. 2326, jan./abr. 2009. Disponível em: http://www.scielo.br/pdf/pci/v14n1/v14n1a03.pdf. Acesso em: 27 jun. 2016. http://dx.doi.org/10.1590/S1413-99362009000100003.

FRANCHETTI, P. No topo da edição universitária. Jornal da UNICAMP, Campinas, 05 nov./11 nov.2012, v. 2012, n. 545, Disponível em: http://www.unicamp.br/unicamp/ju/545/no-topo-da-edicao-universitaria. Acesso em: 28 jun. 2016.

LINDOSO, F. Impressão digital, impressão sob demanda: perspectivas e impasses. In: PUBLISHNEWS. 17 jul. 2012. São Paulo: Carrenho Editorial, 2016.

em:

http://www.publishnews.com.br/materias/2012/07/17/69412-impressaodigital-impressao-sob-demanda-perspectivas-e-impasses. Acesso em: 5 jul. 2016.

LUCCISANO, A.; COP, N.; PACKER, A. SciELO Livros. In: PACKER, A. L., et al. (Org). SciELO - 15 anos de acesso aberto: um estudo analítico sobre acesso aberto e comunicação científica. Paris: UNESCO, 2014. p. 151-170. Disponível em: http://scielo.org/local/File/livro.pdf. Acesso em: 19 jun. 2016. http://dx.doi.org/10.7476/9789237012376.

MARTINS FILHO, P.; ROLLEMBERG, M. EDUSP: um projeto editorial. 2. ed. São Paulo: Ateliê Editorial, 2001.

RODRIGUES, M. A. de S. et al . From print to screen: changes and challenges facing the Brazilian publishing industry. Revista de Administração, São Paulo, v. 49, n. 3, p. 491-505, Sept. 2014. Disponível em: http://www.scielo.br/scielo.php?script=sci_arttext\&pid=S008021072014000300005\&lng=en\&nrm=iso. Acesso em: 20 jun. 2016. http://dx.doi.org/10.5700/rausp1163.

ROSINHA, R. C. Política editorial: aspectos a considerar. Revista de Biblioteconomia de Brasília, Brasília, v. 17, n. 2, p. 249-258, juI./dez. $1989 . \quad$ Disponível em: http://basessibi.c3sl.ufpr.br/brapci/index.php/article/view/0000001754/8 389baf5a5df2daafba3474e9bd66d59. Acesso em: 25 jun. 2016.

SAMPAIO, A. J. Programa Interuniversitário para Distribuição do Livro (PIDL). In: SEMINÁRIO NACIONAL DE EDITORAS UNIVERSITÁRIAS, $6 .$, 1989, Curitiba. Anais [...] Curitiba: UFPR, 1991. 